Article

\title{
Issues and Potential Solutions to the Clean Heating Project in Rural Gansu
}

\author{
Dehu Qv ${ }^{1, *} \mathbb{C}$, Xiangjie Duan ${ }^{1}$, Jijin Wang ${ }^{2}$, Caiqin Hou ${ }^{1}$, Gang Wang ${ }^{1}$, Fengxi Zhou ${ }^{1, *}$ and Shaoyong Li ${ }^{1, *}$ \\ 1 Department of Building Environment and Energy Application Engineering, School of Civil Engineering, \\ Lanzhou University of Technology, Lanzhou 730050, China; dxj2021001@163.com (X.D.); \\ zjshcqzxy@163.com (C.H.); wang_g@lut.edu.cn (G.W.) \\ 2 School of Architecture, Harbin Institute of Technology, Key Laboratory of Cold Region Urban and Rural \\ Human Settlement Environment Science and Technology, Ministry of Industry and Information Technology, \\ Harbin 150090, China; wangijiin126@163.com \\ * Correspondence: QDH000@126.com (D.Q.); geolut@163.com (F.Z.); lishaoyong99@163.com (S.L.); \\ Tel.: +86-931-2973715 (D.Q.)
}

Citation: Qv, D.; Duan, X.; Wang, J.; Hou, C.; Wang, G.; Zhou, F.; Li, S. Issues and Potential Solutions to the Clean Heating Project in Rural Gansu. Sustainability 2021, 13, 8397. https:// doi.org/10.3390/su13158397

Academic Editor: Shervin Hashemi

Received: 20 June 2021

Accepted: 15 July 2021

Published: 28 July 2021

Publisher's Note: MDPI stays neutral with regard to jurisdictional claims in published maps and institutional affiliations.

Copyright: (C) 2021 by the authors. Licensee MDPI, Basel, Switzerland. This article is an open access article distributed under the terms and conditions of the Creative Commons Attribution (CC BY) license (https:/ / creativecommons.org/licenses/by/ $4.0 /)$.

\begin{abstract}
Rural clean heating project (RCHP) in China aims to increase flexibility in the rural energy system, enhance the integration of renewable energy and distributed generation, and reduce environmental impact. While RCHP-enabling routes have been studied from a technical perspective, the economic, ecological, regulatory, and policy dimensions of RCHP are yet to be analysed in depth, especially in the underdeveloped areas in China. This paper discusses RCHP in rural Gansu using a multi-dimensional approach. We first focus on the current issues and challenges of RCHP in rural Gansu. Then the RCHP-enabling areas are briefly zoned into six typical regions based on the resource distribution in Gansu Province, and a matching framework of RCHP is recommended. Then we focus on the economics and sustainability of RCHP-enabling technologies. Based on the medium-term assessment of RCHP in the demonstration provinces, various technical schemes and routes are analysed and compared in order to determine which should be adopted in rural Gansu. In addition to technical and economic effects of those schemes, the corresponding ecology, policy, finance, and market implications are also concerned. We briefly discuss how the national regulators incentivise the implementation of RCHP in rural Gansu. Major barriers to RCHP are identified as the sustainability of technology, economy, ecology, policy, finance, and market. Subsequently, some policy solutions to overcome these barriers are proposed.
\end{abstract}

Keywords: rural clean heating project; rural Gansu; sustainability; potential solutions; benchmarking

\section{Introduction}

\subsection{Building Conservation-Minded Society}

After the first two-decade development in the 21st century, many countries in the world regard "harmonious development between human and nature" as the key of state construction in the next stage, especially after the COVID-19 disaster [1-5]. Particularly, the developed countries in Europe put "renewable energy evolution based new-age industrial revolution" into their national development programs [6-10].

In China, people are confronted with three challenges and/or opportunities: the scientific and technological revolution, the energy revolution, and the ecological revolution. Based on the "development-improvement" experience by western world, Chinese people adopt a sustainable development strategy in building a conservation-minded society (CMS) [11-15].

Energy saving is an important part of CMS, and building energy saving (BES) is the substantial portion [16-18]. Therefore, BES as a national strategic support is in line with the scientific development law.

Through long-term, active, and extensive participation of the whole society, China has made an extraordinary progress in three major sectors of urban residential energy saving, 
public building energy saving, and central heating system energy saving in the north. However, rural China, being the key rear area supporting China's reform and opening-up, faces many challenges from the clean heating project $[17,18]$.

\subsection{Rural Clean Heating Project}

Since 2005, the characteristics of rural housing energy consumption and its composition have undergone profound changes with the promotion of New Rural Construction (NRC (The detailed information about NRC can be taken on http://qgxnc.org/, accessed on 3 February 2021)) and the improvement in peasant farmer's living standards. The most conspicuous variation is rural energy-use structure. Over the past 20 years, the consumption of commodity energy in rural China has been increasing year by year. Meanwhile the consumption of non-commodity energy (biomass energy, especially) has been decreasing $[17,18]$.Furthermore, the total energy consumption in rural areas continues to rise, although the resident population (composed mainly of old people, young children, and school-age children (More information on rural China can be gotten on http: / /www.gov.cn/, accessed on 3 February 2021)) in rural China continues to decline in the meantime, which means that the rural energy-use intensity tends to grow all the time.

On the one hand, increased rural energy demand may indicate the improvement in peasant farmer's living conditions. On the other hand, the lower proportion of renewable energy in rural energy consumption is very worrying, since it works against the low-carbon development path advocated by the government. Therefore, the key to transform energy use in rural China lies in structural optimization of energy use and increase in renewable proportion [18].

Field research shows that the crucial domestic terminals of rural energy use consist of heating, cooking (including domestic hot water), and electricity consumption for household electric appliances and lighting. Among them, wastage from heating accounts for $53.6 \%$ and even more than $60 \%$ of waste in some areas in rural China $[17,18]$. Thus, the rural clean heating project (RCHP) is of great significance to the evolution of CMS in China.

\subsection{Progress of RCHP in Rural Gansu \\ 1.3.1. Current State of Rural Gansu}

Information on the current state of Gansu Province can be found on http:/ /www. gansu.gov.cn/col/col10/index.html, accessed on 3 February 2021. Gansu Province (Figure 1 (Gansu Province map can also be found on http:/ / www.gansu.gov.cn/col/col10/index. html, accessed on 3 February 2021.)) is the provincial administrative region of the People's Republic of China, and its capital is Lanzhou. It is located in the west of China, in the middle and upper reaches of the Yellow River, with a vast area (more than $1600 \mathrm{~km}$ winding from the east to the west, with a total area of $425,900 \mathrm{~km}^{2}$, accounting for $4.72 \%$ of China's total area). There are complex terrains, crisscross mountains, and great differences in altitude. Meanwhile, there are rich mineral resources, wind resources, hydro-power resources, and solar energy resources. The province has a variety of climate types and abundant wildlife. As the birthplace of ancient Chinese civilisation, it has contributed extremely important history and culture to the world.

However, as obvious as the above advantages are, its natural ecology is fragile, the economic development is lagging behind, and the living standard of peasant farmers is low (e.g., the per capita GDP ranking of Gansu Province in China is 31/31 (http:/ /www.gov. $\mathrm{cn} / \mathrm{shuju}$ / chaxun/index.htm, accessed on 3 February 2021.)). Hence, determining how to carry out RCHP in the complex human and geographical environment, while taking into account the regional political and economic characteristics, is the core of RCHP in rural Gansu. 


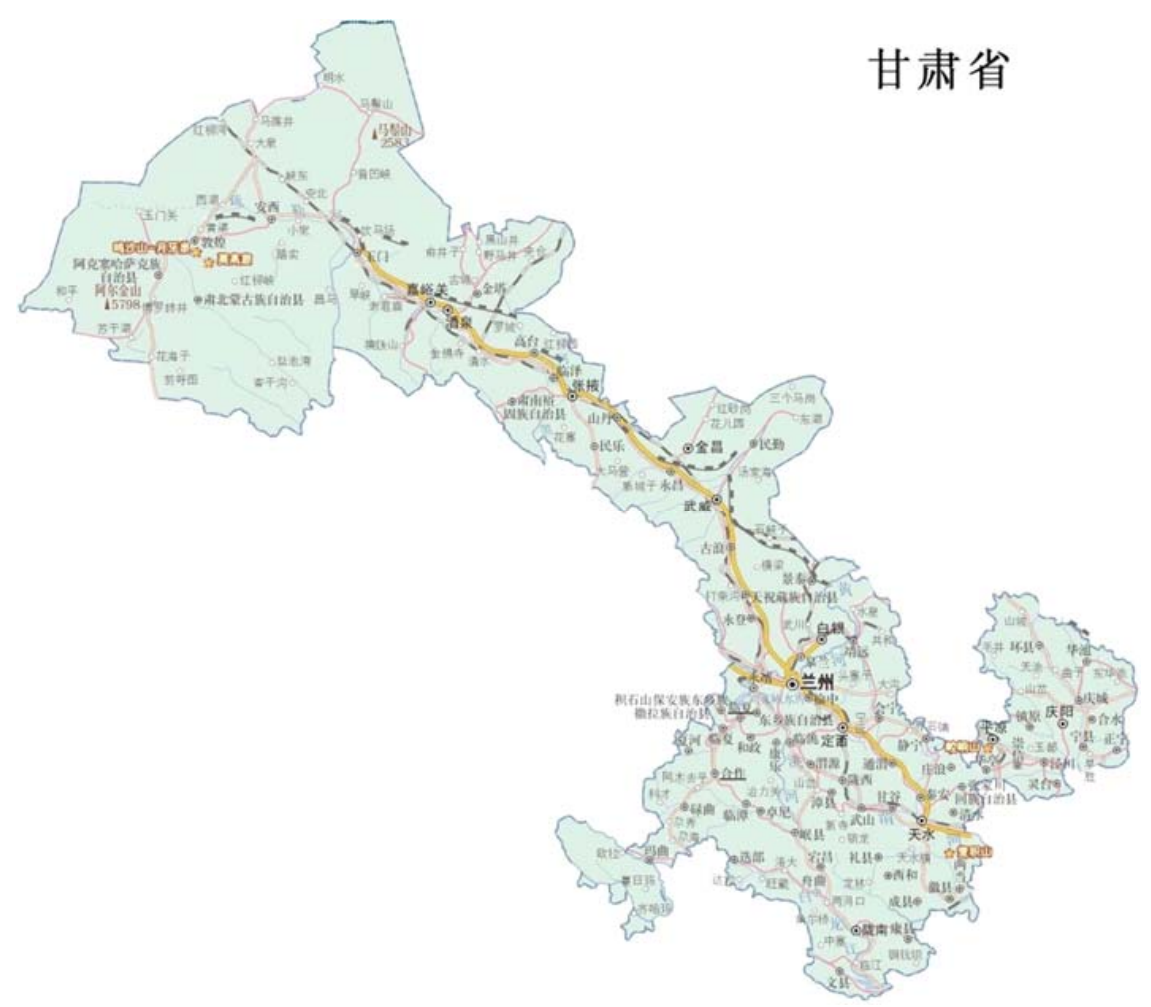

Figure 1. Gansu Province map. Note: This map is provided by http:/ /www.gansu.gov.cn/col/col1 0/index.html, accessed on 3 February 2021.

\subsubsection{Living Energy-Use Reality in Rural Gansu}

Table 1 details the annual consumptions of diverse energy resources in rural Gansu [17,18]. Figure 2 depicts the commercial energy consumption in a comparison with the north average $[17,18]$. It can be found in Table 1 that the total annual energy consumption in rural Gansu is lower than that in the north average, which implies that the peasant farmers' living standard in rural Gansu is lower than that in northern rural China. Fortunately, this living-standard gap has been narrowed since 2006 .

Table 1. Annual consumptions of diverse energy resources in rural Gansu.

\begin{tabular}{|c|c|c|c|c|c|}
\hline Year & Name & Unit & Value & Average & Deviation \\
\hline \multirow{9}{*}{2006} & Total building area & $10^{8} \mathrm{~m}^{2}$ & 3.4 & 5.3 & $-35.8 \%$ \\
\hline & Coal & $10^{4} \mathrm{t}$ & 779 & 1018.9 & $-23.5 \%$ \\
\hline & Liquefied gas & $10^{4} \mathrm{t}$ & 1.2 & 13.5 & $-91.1 \%$ \\
\hline & Power & $10^{8} \mathrm{kWh}$ & 15.7 & 29.4 & $-46.6 \%$ \\
\hline & Firewood & $10^{4} \mathrm{t}$ & 55 & 287.6 & $-80.9 \%$ \\
\hline & Crop straw & $10^{4} \mathrm{t}$ & 92 & 357.1 & $-74.2 \%$ \\
\hline & Commercial energy & $10^{4}$ tec & 610 & 849.4 & $-28.2 \%$ \\
\hline & Non-Com. energy & $10^{4}$ tec & 79 & 348.4 & $-77.3 \%$ \\
\hline & Sum & $10^{4}$ tec & 689 & 1200.5 & $-42.6 \%$ \\
\hline \multirow{9}{*}{2014} & Total building area & $10^{8} \mathrm{~m}^{2}$ & 3.7 & 5.9 & $-37.3 \%$ \\
\hline & Coal & $10^{4} \mathrm{t}$ & 890 & 1056.1 & $-15.7 \%$ \\
\hline & Liquefied gas & $10^{4} \mathrm{t}$ & 3.5 & 14.8 & $-76.4 \%$ \\
\hline & Power & $10^{8} \mathrm{kWh}$ & 16.3 & 46.4 & $-64.9 \%$ \\
\hline & Firewood & $10^{4} \mathrm{t}$ & 45 & 329.7 & $-86.4 \%$ \\
\hline & Crop straw & $10^{4} \mathrm{t}$ & 80 & 352.9 & $-77.3 \%$ \\
\hline & Commercial energy & $10^{4}$ tec & 695 & 928.1 & $-25.1 \%$ \\
\hline & Non-Com. energy & $10^{4}$ tec & 67 & 383.1 & $-82.5 \%$ \\
\hline & Sum & $10^{4}$ tec & 762 & 1311.1 & $-41.9 \%$ \\
\hline
\end{tabular}


Table 1. Cont.

\begin{tabular}{cccccc}
\hline Year & Name & Unit & Value & Average & Deviation \\
\hline & Total building area & $10^{8} \mathrm{~m}^{2}$ & 3.4 & 5.3 & $-35.8 \%$ \\
& Coal & $10^{4} \mathrm{t}$ & 918.8 & 803.6 & $14.3 \%$ \\
& Liquefied gas & $10^{4} \mathrm{t}$ & 4.3 & 13.5 & $-68.1 \%$ \\
& Power & $10^{8} \mathrm{kWh}$ & 20.7 & 58.3 & $-64.5 \%$ \\
& Firewood & $10^{4} \mathrm{t}$ & 46.5 & 265.5 & $-82.5 \%$ \\
& Crop straw & $10^{4} \mathrm{t}$ & 82.6 & 315.5 & $-73.8 \%$ \\
& Commercial energy & $10^{4} \mathrm{tec}$ & 723.6 & 818.5 & $-11.6 \%$ \\
& Non-Com. energy & $10^{4} \mathrm{tec}$ & 69 & 317.1 & $-78.2 \%$ \\
& Sum & $10^{4} \mathrm{tec}$ & 792.6 & 1135.5 & $-30.2 \%$ \\
\hline
\end{tabular}

Note: the commercial energy mentioned in this table includes coal, liquefied gas, and power electricity; the non-commercial energy (Non-Com.) includes firewood and crop straw. The source of data in Table 1 is Reference [17], National Bureau of Statistics of China. China Statistical Yearbook. http://www.stats.gov.cn/tjsj/ndsj/; accessed on 3 February 2021.

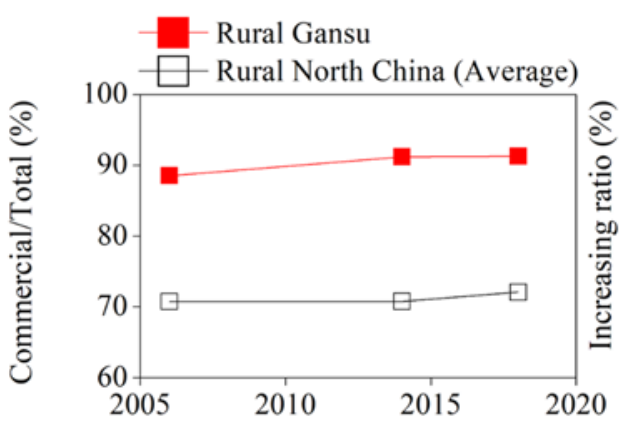

(a)

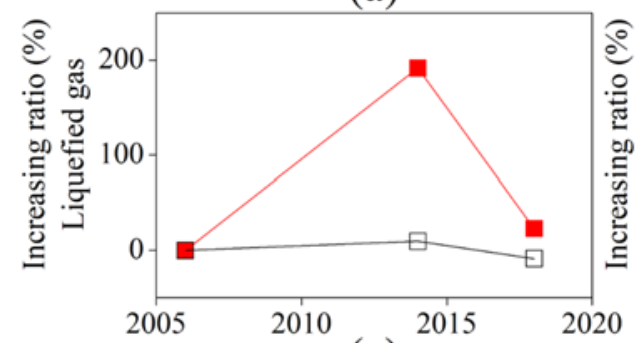

(c)

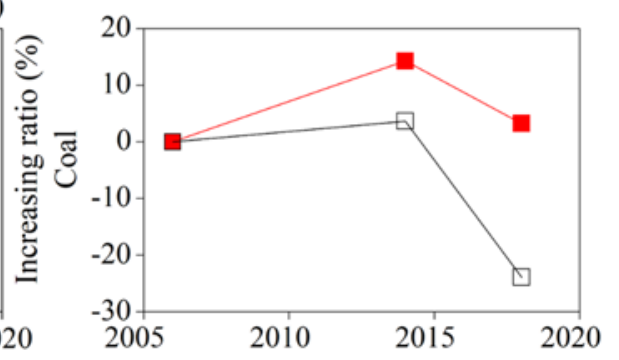

(b)

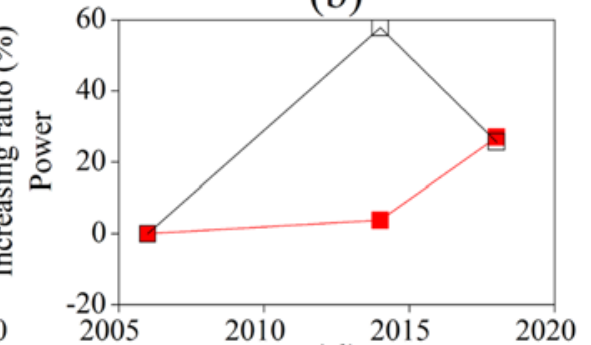

(d)

Figure 2. Commercial energy consumption in rural Gansu; (a) the percentage of commercial energy consumption to total energy consumption; (b) the increasing ratio of coal consumption; (c) the increasing ratio of liquid gas consumption; (d) the increasing ratio of power consumption; Note: The complete data can be found in References $[17,18]$.

On the other hand, in terms of annual commercial energy consumption, its proportion in total energy use in rural Gansu is dramatically higher than that in north average, and this percentage still increases (Figure 2a). Although the coal consumption in the northern rural China has been dropped since 2014, the peasant farmers living in rural Gansu tend to consume more (Figure 2b). The liquefied-gas consumption shows a similar trend in past years as Figure $2 \mathrm{c}$ depicts. By contrast, the increasing rate of power consumption in rural Gansu is accelerating, which is contrary to the slowing-down tendency in the northern rural China (Figure 2d) [17,18].

Based on the other studies we can understand that there is a significant gap between energy-use demand and energy supply in rural Gansu, and there is a great divergence between its energy structure and the sustainability goals of China [11-16]. Furthermore, the contradictions existing in the peasant farmers' living conditions and their health targets are obvious [18]. In particular, the indoor air temperatures in rural Gansu are generally low with cold air infiltration, and the indoor air quality is poor caused by coal combustion [18]. 


\section{Challenges}

This section firstly summarises mutual issues of the clean heating project in northern rural China. Then, the specific issues in rural Gansu, which make the advance in RCHP in rural Gansu harder, are introduced from different aspects.

\subsection{Mutual Issues in Northern Rural China}

Mutual issues in northern rural China have been studied carefully in the reference [18].

(1) Different from the cities with concentrated population, the rural population is scattered and forms a small-scale settlement pattern with villages as the main administrative unit. Thus, rural building energy saving should be carried out by villages.

(2) A combination of production and living functions has made rural houses special. The farmhouses have large courtyards, mostly vacant or idle rooms, and are mainly single storey or low-rise buildings.

(3) The traditional lifestyles in the northern rural areas have a profound impact on the energy consumption of heating and cooking: (1) In the cold winter, peasant farmers spontaneously integrate some room functions to reduce the number of heating rooms and shorten the heating hours. (2) Peasant farmers' clothing level is based on the shortterm outdoor work "not cold", and their clothing is thicker. In the meantime, peasant farmers do not adapt to the large indoor-outdoor temperature difference. Hence the indoor design temperature of rural residential buildings in winter is generally lower than $16^{\circ} \mathrm{C}$, conventionally ranged $10-15^{\circ} \mathrm{C}$. (3)The thrifty living habits of Chinese peasant farmers, together with the traditional ways of life and labour, jointly determine the heating characteristics of "part of the time and part of the space" in northern rural China, and thus generate the heating demand of "room regulation; use as you go; one key operation".

(4) The midterm assessment for the northern RCHP, which started in 2016, was completed. By the end of 2018, the clean heating rate of the regions participating in the project has exceeded the medium-term target $[17,18]$. During this period, a series of clean heating schemes suitable for rural areas in northern China have been verified, which include coal to electricity, coal to gas, coal to biomass, solar based multi energy complementation, and coal to central heating $[17,18]$. Each scheme has different applicable conditions, advantages, and disadvantages, which are detailed in Tables 2-5 (The corresponding data come from the reference [18]). In particular, the scheme of coal to central heating is only suitable for cogeneration and industrial surplus heat recovery, which require speasant farmers to live in concentrated dwellings, so that the transmission and distribution pipes will not be too long [19-25].

(5) Other problems exposed in practice include: (1) there is a lack of coordination among departments as well as there are conflicts among policies, whereas such conflicts are usually ignored because people tend to consider the disharmony as a symbol that each department performs its own tasks; (2) financial subsidies do not fully consider the differences (economic, environmental protection, sustainability, etc.) between various technical schemes; (3) the economic incentive policy is not clear enough, and the subsidy is insufficient; (4) the government needs stronger scientific guidance of planning and technical path, and the overall consideration of follow-up operation and maintenance; (5) part of the implementation plan is too rough, which directly affects the enthusiasm of peasant farmers' participation; (6) the operation mechanism of marketisation is unsound, which relies too much on government subsidies, and financing is difficult; (7) the sustainable development and long-term market mechanism have not yet formed, and it is difficult for peasant farmers to bear fully without the subsidy; (8) the lack of quantitative evaluation mechanism makes it difficult to revise the technical route in time $[17,18]$. 
Table 2. Assessment of coal to electricity.

\begin{tabular}{ll}
\hline Name & Details \\
\hline Optimum scheme & Low-temperature air source heat-pump air heater \\
\hline Technical advantages & $\begin{array}{l}\text { At present, China is in the leading position in the application fieldin the world. } \\
\text { The heat-pump products can provide reliable and efficient heating whilethe ambient temperature } \\
\text { is higher than }-30^{\circ} \mathrm{C}, \text { which covers most of climatic regions with heating demand in China. }\end{array}$ \\
\hline Economical advantages & $\begin{array}{l}\text { The power consumption of each household in a whole heating season is less than } 2000 \mathrm{kWh} . \\
\text { Even if there is no electricity subsidy, the total cost is less than } 1000 \mathrm{RMB} .\end{array}$ \\
\hline Common advantages & $\begin{array}{l}\text { The demand of external power capacity is small, and there is no need for special rural power grid } \\
\text { upgrading. }\end{array}$ \\
\hline Using advantages & $\begin{array}{l}\text { One key operation; hot air output; without water pump energy consumption; without water loop } \\
\text { leakage; without antifreeze or other issues. }\end{array}$ \\
\hline Summary & It is anideal technical scheme widely suitable for RCHP in China.
\end{tabular}

Table 3. Assessment of coal to gas.

\begin{tabular}{ll}
\hline Name & Details \\
\hline Economic disadvantages & $\begin{array}{l}\text { The price of gas is higher than the psychological acceptance price of peasant farmers, which leads } \\
\text { to the gas company spending a lot of money to build the gas pipeline network, but the actual } \\
\text { effective utilisation rate is low, preventing obtainment of an investment return. }\end{array}$ \\
\hline Safety disadvantages & $\begin{array}{l}\text { There are common safety hazards, involving products, installations, constructions, operations, } \\
\text { and daily safety awareness. }\end{array}$ \\
\hline Common disadvantages & The pressure of gas resources is great, and gas companies generally suffer serious losses. \\
\hline Financial disadvantages & $\begin{array}{l}\text { The subsidy input is large and increasing year by year, resulting in a heavy financial burden on } \\
\text { the local government. }\end{array}$ \\
\hline Summary & This scheme is almost unacceptable in northern rural China \\
\hline
\end{tabular}

Table 4. Assessment of coal to biomass.

\begin{tabular}{ll}
\hline Name & Details \\
\hline Optimum solutions & $\begin{array}{l}\text { Plan A: Hot air type biomass pellet heating furnace } \\
\text { Plan B: Hot water type biomass granule heater }\end{array}$ \\
\hline & $\begin{array}{l}\text { Plan A: Compared with scheme of coal to gas, the transformation cost is reduced by } 38 \% \text { and the } \\
\text { operation cost is reduced by } 52 \% \text {. In areas rich in biomass resources, it is worth promoting. } \\
\text { Plan B: In addition to heating load, it also takes into account the demand of cooking and domestic } \\
\text { hot water, and closely fits with the traditional living habits of peasant farmers. At present, this } \\
\text { technology has been fully automated, intelligent, has one key operation, and is convenient and } \\
\text { safe. Even without government subsidy, each household consumes about } 1.5 \text { t biomass particles } \\
\text { in a whole heating season, and the heating cost is about } 1000 \text { RMB, which is equivalent to the cost } \\
\text { of burning bulk coal, but it is more convenient and environmentally friendly. }\end{array}$ \\
\hline Technical defects & $\begin{array}{l}\text { The current biomass particles are mainly wood, which cannot make full use of more abundant } \\
\text { crop straw resources. }\end{array}$ \\
\hline Market defects & Furnace products lack standard specifications. \\
\hline Industrial defects & $\begin{array}{l}\text { The market specialisation of biomass energy industry chain is low, and the complete system has } \\
\text { not yet formed. } \\
\text { The national and local governments have not given clear opinions on the environmental } \\
\text { protection requirements of biomass energy, resulting in many regions still waiting. }\end{array}$ \\
\hline
\end{tabular}


Table 5. Assessment of solar based multi energy complementation.

\begin{tabular}{ll}
\hline Name & Details \\
\hline Mainstream technologies & $\begin{array}{l}\text { Integrate solar energy collection system with electric energy, natural gas, or other } \\
\text { energy sources to provide hot water or hot air for peasant farmers. }\end{array}$ \\
\hline Technical and economical disadvantages & $\begin{array}{l}\text { This system is usually complex. In order to ensure the reliability of unattended, solar } \\
\text { energy is often abandoned and auxiliary heat source is used instead, which is contrary } \\
\text { to the original intention of clean heating. }\end{array}$ \\
\hline Sustainability disadvantage & $\begin{array}{l}\text { The system control is complex, and there is large amount of operation and } \\
\text { maintenance, which is not suitable for rural areas. }\end{array}$ \\
\hline
\end{tabular}

\subsection{Special Issues in Rural Gansu}

Special issues in rural Gansu can be found on http:/ / www.gansu.gov.cn/col/col10/ index.html, accessed on 3 February 2021.

\subsubsection{Resource Distribution}

(1) Land. The unused land is concentrated in the north, and dry land is concentrated in the southeast. The woodlands are scattered along the southeast border, and pastures are concentrated in the southwest.

(2) Mineral resources. The nonmetal resources are mainly distributed in the south-central part of the province, and metal minerals are distributed in the whole province, but more in the south.

(3) Clean energy. It is mainly distributed in the west and north of Jiuquan and Jiayuguan line.

(4) Circular economy base planned by the government. Zhangye-Wuwei-Dingxiarea is thecircular economy base for processing characteristic agricultural and sideline products. Gannan-Linxia-Longnan area is the base of ecological circular economy. Other areas are heavy industry and general industrial bases.

(5) Human resources. There are few higher education institutions in the province, and they are concentrated in the provincial capital. Restricted by economy, human settlements, and other factors, all kinds of talent-introduction work lags far behind other provinces. Further, even the talent exchange with neighbouring Shaanxi Province is not frequent, and the development of information and technology is lagging behind.

\subsubsection{Population Distribution}

They are mainly distributed in Gannan-Linxia-Longnan area, or around the provincial capital, and in various industrial areas. In the area west and north of the Jiuquan-Jiayuguan area, which is rich in clean energy, the natural conditions are hard and the population is sparse.

\subsubsection{Economic Distribution}

Rural poverty is generally deep, showing a spatial pattern of "high in the southeast and low in the northwest". The spatial agglomeration characteristics of rural economy and social poverty are significant. The spatial pattern of environmental poverty is "high on both wings and low in the middle".

\subsubsection{History and Culture}

With a long history and culture, traditional notions are deeply rooted in the hearts of the natives. On the one hand, the common customs of thrift and simplicity still exist. On the other hand, there is little internal motivation for new things and trends.

\subsubsection{Ecological Environment}

(1) Water environment. Precipitation decreases from southeast to northwest, and water resources per capita is low. For example, the average annual precipitation of the 
whole province is $398.5 \mathrm{~mm}$, which is less than the national average $(632 \mathrm{~mm})$. It is one of the provinces with the least precipitation in China. About $70 \%$ of the area has annual precipitation less than 500 mm (http: / www.gansu.gov.cn/col/col2085/index.html, accessed on 3 February 2021.).

(2) Atmospheric environment. Although the air quality has been improved, it is still disturbed by dust.

(3) Land environment. The effectively used area of land is small. Soil fertility remains weak, and soil erosion and desertification are still serious.

(4) Self repair function. The Yellow River Basin is dry and rainless all the year round, the river runoff is small, the self purification ability is feeble, and the ecological environment is still fragile.

\section{Framework of RCHP in Rural Gansu}

\subsection{Rural Residential Insulation Transformation}

So far, the proportion of residential insulation in rural Gansu is about $2.6 \%$, while it is $30.7 \%$ in Beijing $[17,18]$. Thus, there is greater improvement potential, which is the first step of RCHP.

\subsubsection{Existing Farmhouse}

In accordance with the characteristics of rural residential heating demand, internal thermal insulation (ITIS) is more suitable for the external wall. Compared with external insulation, internal insulation is simpler, which supports the use of local rooms and reduces indoor continuous operation area. Thus, the construction is safer and more convenient, which is conducive to improve construction efficiency and reduce labour intensity. In addition, the construction is not affected by outdoor climate.

The overall implementation principles of ITIS include low-cost targeted thermal insulation and extra insulation that comprises of external doors and windows. The mentioned targeted thermal insulation means that the frequently used rooms are insulated first. Repairing roofs and insulating north facing external walls have priority over the others. In the meantime, sunlight in the south should be fully used, and interiorceiling can be increased to reduce indoor floor height. When the selected insulated materialispolymer resin, total investment of the whole household is about $2275 \mathrm{RMB}$, and the comprehensive energy saving ratio is about $30 \%$ [18]. If the budget is still sufficient, extra insulation should be considered. Here the total investment of the whole household will be increased by $1325 \mathrm{RMB}$, and the comprehensive energy saving rate will be about 35\% [18].

\subsubsection{New Farmhouse}

When the funds are limited, we can adopt the insulation route for existing rural houses. If the fund is surplus, by contrast, the overall insulation of the enclosure structure can be considered.

Straw board and brick insulation is preferred in wheat, pasture, and grass production areas. The thermal conductivity of dry grass leaves is about $0.1 \mathrm{~W} /(\mathrm{m} \cdot \mathrm{K})$, which is equivalent to that of cement-based perlite. The heat transfer coefficient of a $330 \mathrm{~mm}$ straw brick wall is about $0.3 \mathrm{~W} /\left(\mathrm{m}^{2} \cdot \mathrm{K}\right)$, which is about $1 / 3$ of that of $370 \mathrm{~mm}$ red brick wall [18]. At present, the technology has been successfully applied in demonstration projects in Gansu and Heilongjiang provinces, and the overall cost per unit building area is 600-700 RMB $/ \mathrm{m}^{2}$, which is lower than that of conventional brick-and-tile houses [18]. In the absence of biomass raw materials, new insulation blocks can be considered as external wall insulation and foam cement roofs as roof insulation. This technology has been used for many years in the north of China. It is mature, reliable, and economical. In addition, PVC plastic window and glass fiber reinforced plastic window have good thermal insulation performance with relatively low price, which are proper insulation solutions for rural China. 


\subsubsection{Relevant Issues}

Relevant issues in rural Gansu can be found on http:/ /www.gansu.gov.cn/col/col10/ index.html, accessed on 3 February 2021.

(1) Gansu Province belongs to cold climates, so that the casement windows rather than sliding windows should be adopted.

(2) The fire-resistant rate of internal insulation materials is required to be B1 and above. In the meantime, safety awareness of peasant farmers must be improved.

(3) The condensation phenomenon on the inner surface of external wall is rare because indoor heating temperature of rural houses is low, absolute moisture content of air is small, and its dew point temperature is lower.

(4) There is an air layer between the insulation material and the inner surface of the external wall, and the upper part of the air layer is connected with the ceiling to ensure smooth exhaust of moisture.

(5) There is no risk of condensation in the overall external insulation structure as the previous research demonstrated [26].

\subsection{Clean Heating Route}

(1) The basic principles include: (1) divide the implementation with the characteristics of resources distribution (including material, energy, population, economy, etc.); (2) take ecology as the fundamental, and efficiently use the regional resources; (3) streamline configurations and technologies.

(2) Reasonably exploit the biomass energy without wasting, nor impairing the development of wind power, hydropower, photovoltaic power, etc.

(3) The cost of energy transmission and distribution must be carefully calculated and compared among various RCHP schemes. The main stream technique is the distributed energy system technique.

(4) Pay attention to the technical economy and check the payback period and sustainability of the scheme.

(5) Under the guidance of the government, green development funds for poor and backward areas should be set up to support clean heating enterprises to issue green bonds and support the flow and exchange of talents.

(6) Draw lessons from advanced experience, establish clean heating standards and specifications led by the government, and introduce independent supervision of the third party.

(7) Support and guide peasant farmers' self-organized biomass cooperatives, and conduct the biomass-energy poverty alleviation and development project based on the rational use of tax lever.

\section{Methods}

Figure 3 draws the methodological map of this study, which also plots the underlying connections among various methods and tools.

\subsection{Investigation and Survey}

The sources of data are statistical data by National Statistical Yearbook, micro survey results from individual or organ interview, modelling data stemmed from CBEM by Tsinghua University, and comprehensive summary of measured data which provided by a range of independent research.

\subsection{Benchmarking}

In this section, we are concerned with demographic factors, natural environmental factors, cultural and historical environmental factors, human resource factors, natural resource factors, economic factors, and policy factors. 


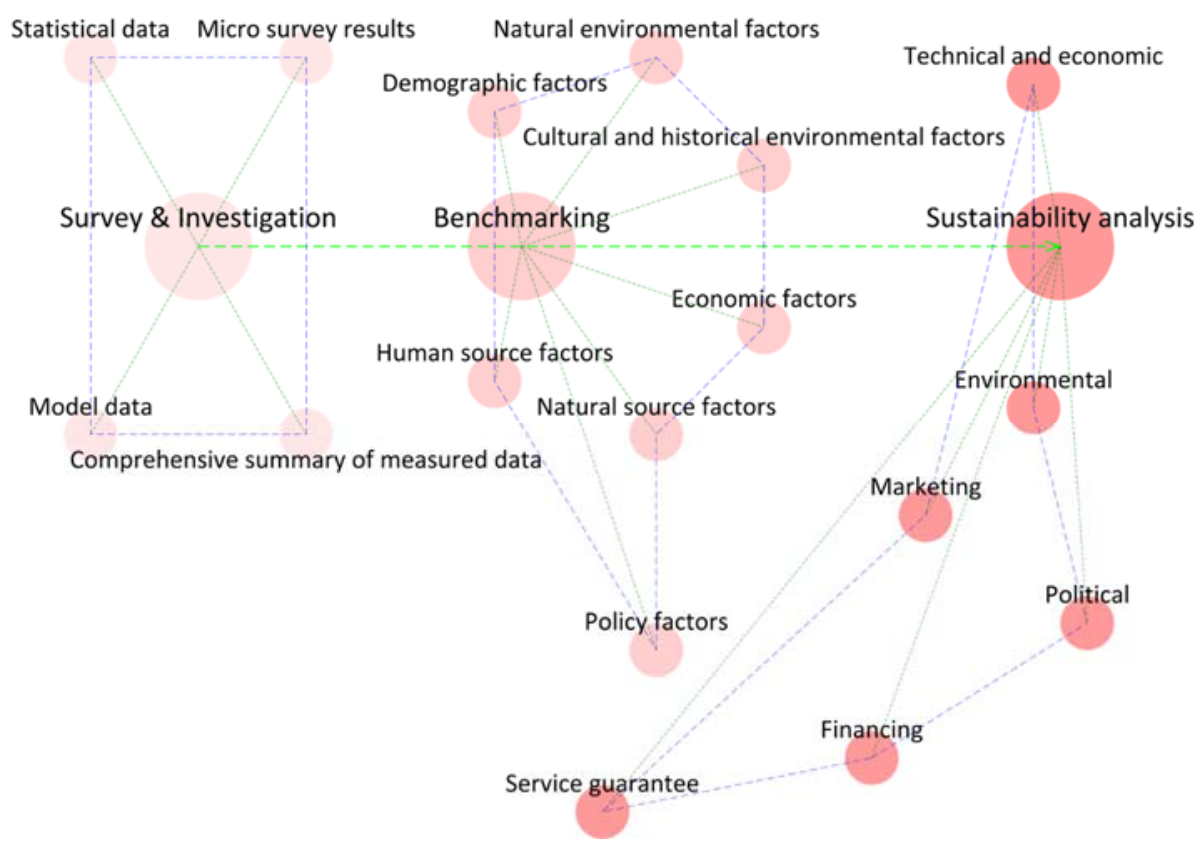

Figure 3. Methodological map.

\subsection{Sustainability Analysis}

Sustainability analysis covers technical and economic, environmental, political, marketing, financing, and service-guarantee aspects. More specifically, the adopted technologies have to be reliable, renewable (avoid using high quality energy in a low-quality way), and economical (the investment is less and the payback period is short). Owing to an originally fragile ecology in Gansu Province, environment protection has to be the fundamental of development. Pollution-treatment route cannot be considered. Quantifying environmental impact indexes, assessing various technical solutions, and often revising technology roadmap is necessary and significant.

Additionally, policies must stand the test of time and the policy makers must abandon opportunism and concentrate on long-term development. Subsidy policies should be different in accordance with various technical and economic indicators of different schemes. Policy formulation, implementation, and supervision must be managed systematically. With respect to the market, the adopted scheme should be helpful to improve the market mechanism and establish a sustainable market order, which is commercially viable, even if preferential policies are absent. Meanwhile, the product quality must be strictly supervised and controlled, and a complete supporting industry chain that serves RCHP is necessary. Moreover, the government must lead the establishment of green development funds, and actively encourage the introduction of social capital to benefit the people. Step by step, a benign operation model of "enterprise oriented, government driven and residents affordable" can be set up. Ultimately, a circular ecology is formed based on long-term planning of the government, which carries out the biomass-based poverty alleviation project and supports (and guides) peasant farmers to build their own ecological home.

\section{Results and Discussion}

In this part, the information sources are taken on http://www.gansu.gov.cn/col/col1 0/index.html, accessed on 3 February 2021.

\subsection{Longdong Zone with Grass Field Ecological Agriculture and Animal Husbandry Industrial Area}

\subsubsection{General Principles}

The arid and semi-arid hilly areas in Eastern Gansu Province are grassland zonal vegetation. Based on the link between Leguminosae and Gramineae, the dry farming 
farmland will be rotated in the Loess Plateau to improve the soil fertility and develop the family breeding of cattle, pigs, sheep, and chickens with grass feed.

In order to prevent soil erosion and desertification, it is necessary to take returning farmland to forest and grassland as the main direction for the ridge, hill and gully land with serious soil and water loss. In the meanwhile, establish a farmland shelterbelt system with shrubs as the main component and trees, shrubs, and grasses combined, to improve the conditions of agricultural production. Take feed processing as the leader to increase the utilisation rate of feed and other plants and enhance the output of livestock products.

Based on the initial investment constraints and operating cost constraints, we should focus on the long-term development of this zone and form a household-scale biomass energy cogeneration model.

\subsubsection{Energy Saving Based on Thermal Insulation of Rural Buildings}

The rural houses in this area are mainly rebuilt. Based on the full biomass resources in this zone, we adopt the overall insulation structure of straw board and brick. The cost of external wall is about $125 \mathrm{RMB} / \mathrm{m}^{2}$, the cost of external window is about $320 \mathrm{RMB} / \mathrm{m}^{2}$, and the cost of roof insulation is about $50 \mathrm{RMB} / \mathrm{m}^{2}$. The overall cost of unit building area ranges from 600 to $700 \mathrm{RMB} / \mathrm{m}^{2}$, which is slightly lower than that of conventional brick-and-tile houses. The average heating energy saving of each household is more than $30 \%[17,18]$.

\subsubsection{Construction of Biomass Industry Cycle}

This project benchmark is the nearly zero carbon emission mode of biomass cogeneration with "gas-electricity-heat-fertiliser" cycle in Ping'an County, Hebei Province. This project takes households as the unit based on the water collection and storage facilities. A household-scale cogeneration pattern with efficient planting, house feeding and breeding, and biogas energy supply is set up to coordinate the contradictions among gas, electricity, heat, and fertiliser.

We take Pingliang and Qingyang as project demonstration areas, based on the ecological compensation mechanism, and make full use of clean coal and power resources in Pingliang, and water conservation in Qingyang, and gradually promote the dry farming circular ecological agriculture mode with unit of households (Figure 4 [27]).

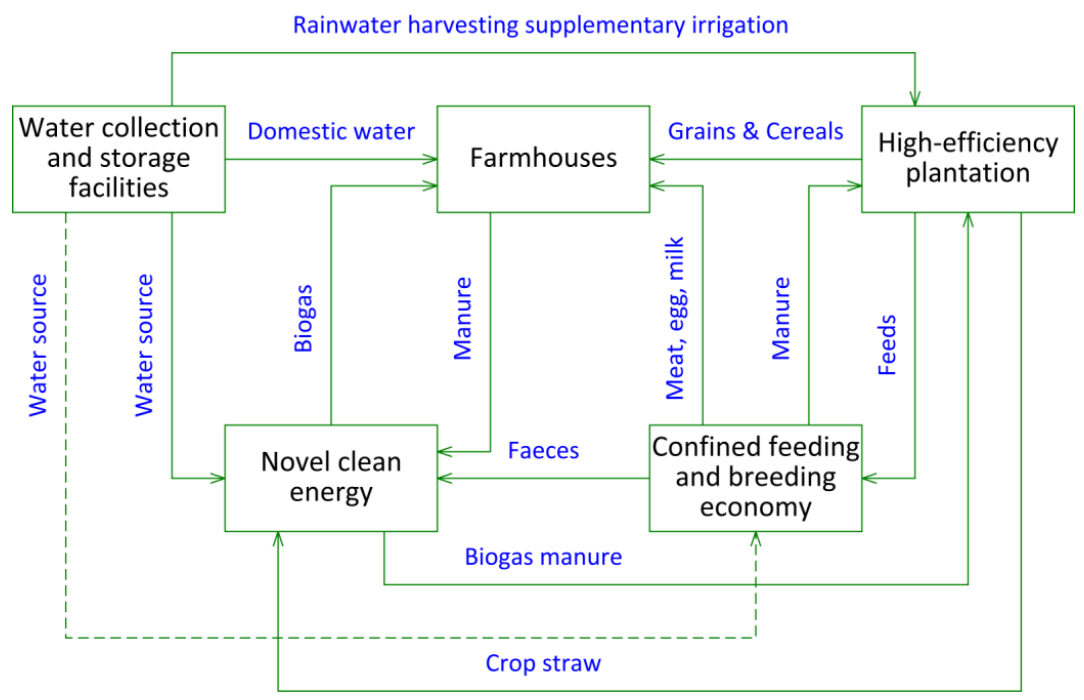

Figure 4. Schematic of dry farming circular ecological agriculture mode; Note: The detailed information about Figure 4 can be found in Reference [27]; S L Jin. Investigation on the model of dry farming circular ecological agriculture with farmer as unit in semi-arid rain fed agricultural area of Gansu Province. Communication of Agricultural Science and Technology; 2011, (2): 11-3. 
The expected operation effects include: (1) the centralised treatment rate of sewage is more than $91 \%$; (2) the treatment rate of domestic waste is more than $99 \%$; (3) the recycling rate of wasted agricultural film is more than $83 \%$; (4) the comprehensive utilisation rate of large-scale livestock and poultry breeding waste is more than $97 \%$; (5) the comprehensive utilisation rate of crop straw is more than $84 \%$; (6) the annual utilisation rate of waste is $12,000 \mathrm{t} / \mathrm{MW}$; (7) the annual productivity of combustible gas is $3-40$ million $\mathrm{m}^{3} / \mathrm{MW}$, replacing standard coal by $3000 \mathrm{t} / \mathrm{MW}$; (8) reduction of $72 \mathrm{t} / \mathrm{MW}$ of sulfur dioxide, $22 \mathrm{t} / \mathrm{MW}$ of nitrogen oxide, and $7200 \mathrm{t} / \mathrm{MW}$ of carbon dioxide; (9) $2400 \mathrm{t} / \mathrm{MW}$ of solid carbon and $1800 \mathrm{t} / \mathrm{MW}$ of organic matter active extract obtained; (10) the income of peasant farmers is increased by $3100 \mathrm{RMB} /$ capita [18].

\subsection{Longxi Dry Farming and Rain Collecting Agricultural and Livestock Industrial Area 5.2.1. General Principles}

The agricultural industrialisation mode of Rainfed irrigation in Longxi is developed by the local people in long-term agricultural practice. The key of this model is to collect water for irrigation and improve the utilisation rate of precipitation.

In order to solve the energy problem in rural areas, it is necessary to return farmland to forest and grass, expand the vegetation coverage, and combine the engineering measures to renovate the barren mountains and ditches, build fuel forest.

The development of animal husbandry in agricultural areas enhances organic fertiliser for crop production, improves soil fertility, and achieves positive interaction. In order to build a sound carbon cycle, we need to tap the regional woody biomass energy.

\subsubsection{Energy Saving Based on Thermal Insulation of Rural Buildings}

The rural houses in this area are mainly rebuilt. In order to fully use the regional biomass resources, we adopt the economic targeted thermal insulation system. North facing exterior wall is internally insulated with $30 \mathrm{~mm}$ polymer resin of $35 \mathrm{RMB} / \mathrm{m}^{2}$. Indoor ceiling is insulated by $30 \mathrm{~mm}$ polymer resin of $35 \mathrm{RMB} / \mathrm{m}^{2}$. The total investment of the whole household is about $2275 \mathrm{RMB}$, and the comprehensive energy saving rate is about 30\% [17,18].

As for households with good financial conditions, we can attach external window thermal curtain $\left(60 \mathrm{RMB} / \mathrm{m}^{2}\right)$ and external door thermal curtain $\left(60 \mathrm{RMB} / \mathrm{m}^{2}\right)$. The total investment of the whole household (including external wall and ceiling reconstruction costs) is about $3600 \mathrm{RMB}$, and the comprehensive energy saving rate is about 35\% [18].

\subsubsection{Distributed Biomass Energy System}

This project benchmark is intelligent biomass pellet fuel heating furnace in Beichuan County, Sichuan Province. It sets up biomass pellet fuel processing stations in villages to realise the pattern of self-production for self-use, and interconnecting villages and towns. We take Longxi as the demonstration area and build an organic agriculture integrated with biomass cycle model.

The expected operation effects include: (1) the processing capacity of each hundred square meters (workshop) is 30-40 t/month, and the charge standard for the substitute processing is about $400 \mathrm{RMB} / \mathrm{t}$; (2) biomass fuel is local collection and production, bringing additional income of 100-200 RMB/t for peasant farmers; (3) the original living (and cooking) habits of peasant farmers are not changed, and the cleaning stove spontaneously realises cooking and heating; (4) the biomass stove is directly installed indoors and heated up fast and effectively; (5) the combustion efficiency of burner reaches more than $95 \%$, the thermal efficiency of rated working condition reaches more than $80 \%$, the thermal efficiency of cooking reaches more than $40 \%$, and the waste heat recovery efficiency of flue gas reaches more than 10\%; (6) the daily consumption of biomass fuel for each household is not more than $1 \mathrm{~kg}$, and the annual fuel consumption is about $8-12 \mathrm{RMB} / \mathrm{m}^{2}$, saving more than $80 \%$ of fuel consumption compared with conventional firewood stoves; (7) the pollutant emission is reduced by $90 \%$ and the indoor air quality is significantly improved; (8) the 
agricultural and livestock wastes such as dead branches and leaves, crop straw, livestock manure, and other biomass wastes are reasonably consumed, the heating expenditure is decreased, and the peasant farmers' income is increased in disguised form [18].

\subsection{Longnan Mountainous 3D Ecological Characteristic Agricultural Area \\ 5.3.1. General Principles}

Basic farmland with high and stable yield is built on both sides of the river valley with good water and heat conditions and on the gentle low hillside to ensure food demand. Convert farmland to forests, plant economic forests and firewood forests, and develop diversified management in the areas close to the mountains and steep slopes.

In the area that is not suitable for planting economic forests, we need to plant trees, shrubs, and grasses to increase vegetation coverage, store soil and water, and improve ecological environment. Remote mountains are built as ecological forests. Briefly, in this zone, we should fully use the regional advantages of abundant woody biomass to build a unique model of forest economy.

\subsubsection{Energy Saving Based on Thermal Insulation of Rural Buildings}

The rural houses in this area mainly focus on energy-saving transformation, and adopt economic targeted thermal insulation system, which is consistent with the technical route adopted in Longxi area. Meanwhile, we need to fully concern the humid climate of this region.

\subsubsection{Distributed Biomass Energy System}

This project benchmark is intelligent biomass pellet fuel heating furnace in Raoyang County, Hebei Province. It fully uses the forest advantages to establish biomass particle fuel processing stations with the unit of villages and realises the pattern of self-production for self-use, and village interconnection.

Here we take Tianshui, Dingxi, and Longnan as demonstration areas, and establish a virtuous cycle of biomass fuel processing and consuming. The expected project operation effects can be seen by examining the case in the Longxi zone.

\subsection{Gannan-Linxia Artificial Ecological Grass and Livestock Industry Area \\ 5.4.1. General Principles}

Here the climate is cold and humid with obvious difference in vegetation types. There are high-quality grassland and rich forests, so that we can boost the intensive and longchain development of grass and livestock industry, based on the artificial and semi artificial grassland. In accordance with the constraints of initial investment and operating costs, the government has to focus on the long-term development of this zone, and gradually sets up a complete industrial biomass cycle.

\subsubsection{Energy Saving Based on Thermal Insulation of Rural Buildings}

The rural houses in this zone are mainly rebuilt, which is consistent with the technical route adopted in Longdong area. Meanwhile, the cold and humid climate of this region should be carefully considered.

\subsubsection{Construction of Biomass Industry Cycle}

This project benchmark is the nearly zero carbon emission mode of biomass cogeneration with "gas-electricity-heat-fertiliser" cycle in Ping'an County, Hebei Province. We make full use of the regional ecological advantages and abundant water resources in Linxia to build a new ecological agriculture model of efficient planting integrated with breeding and regional biogas ecological tourism. Subsequently, we promote a large-scale cogeneration of gas, electricity, heat, and fertiliser.

In this zone, 4958 administrative villages are involved, and the total investment in ecological construction is 19.41 billion RMB (The mentioned data come from http: 
/ /www.gansu.gov.cn/col/col10/index.html, accessed on 3 February 2021.). Based on the technical route of biomass waste plus clean energy plus organic fertiliser, a complete cogeneration pattern is set up with multi-level utilisation of resources and material virtuous recycling (Figures 5 and 6 [28]). The expected project operation effects can be referred to the case in the Longdong area.

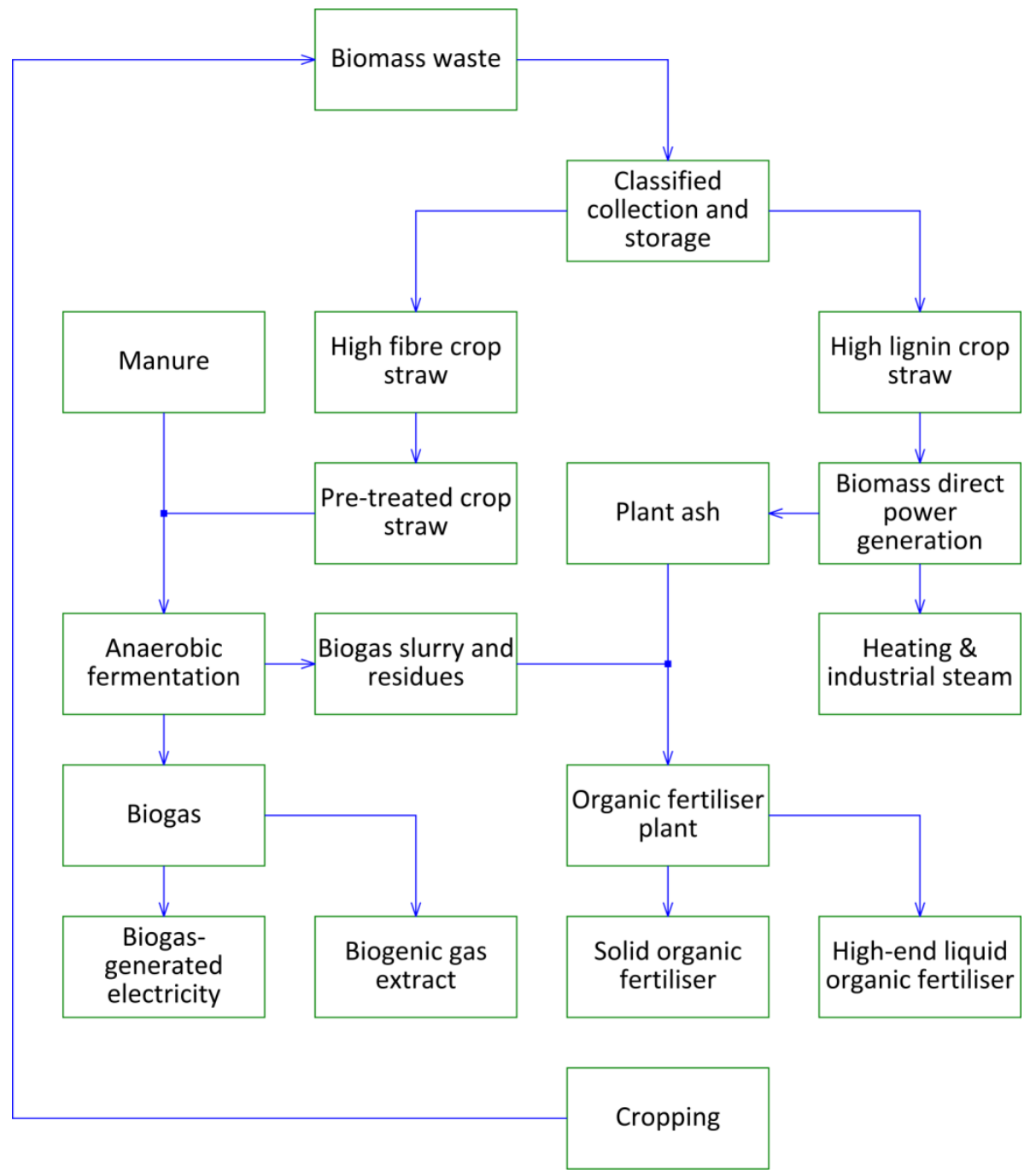

Figure 5. Gas-electricity-heat-fertiliser cogeneration mode. 


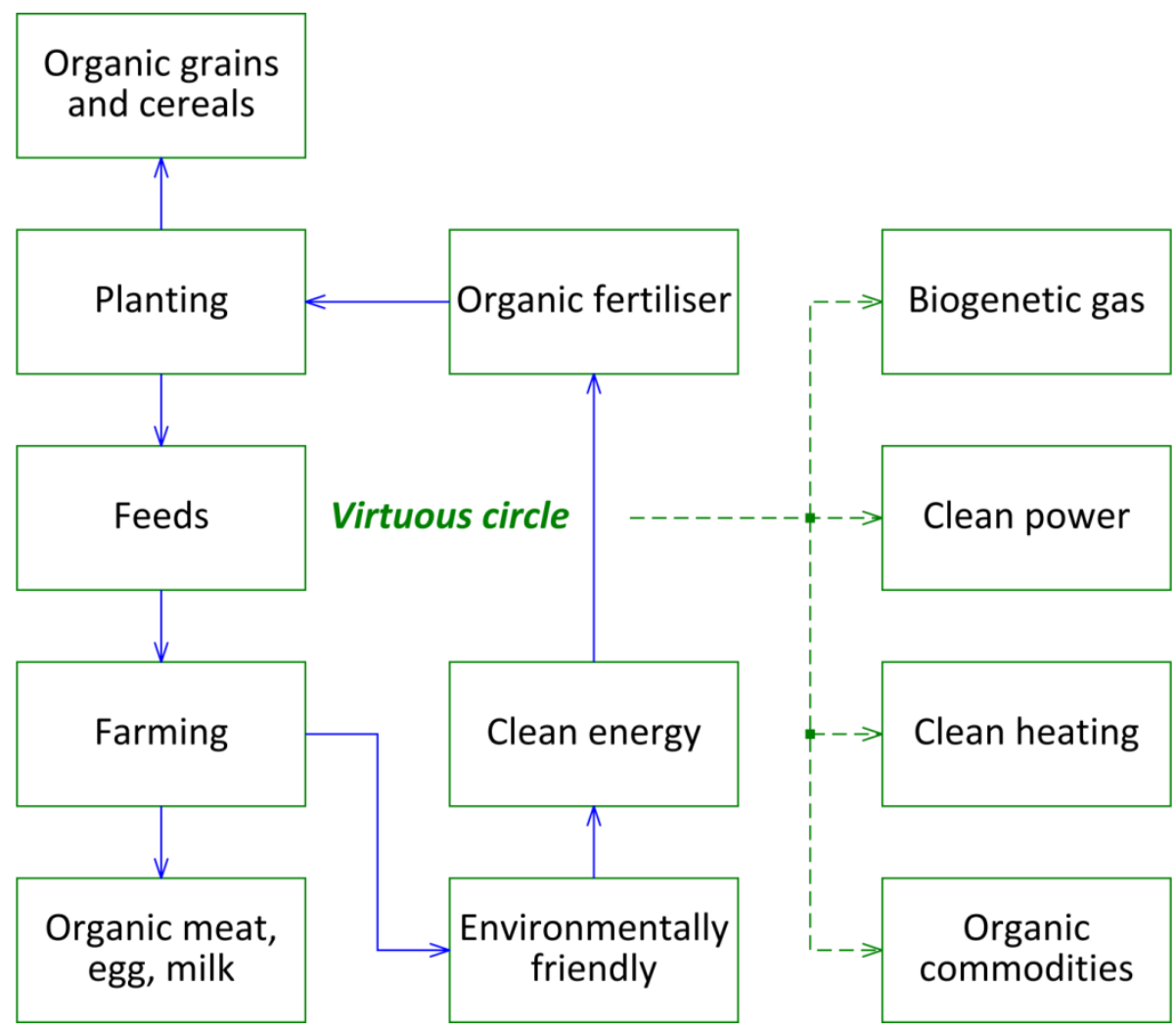

Figure 6. Schematic multi-level utilisation of resources and material virtuous recycling; Note: The detailed information about Figures 5 and 6 can be found in Reference [28]; W He. A preliminary study on the mode of comprehensive agricultural development for poverty alleviation and ecological environment improvement in the poverty stricken mountainous areas of central and southern Gansu Province. Communication of Agricultural Science and Technology; 2008, (16): 16-7.

\subsection{Hexi Corridor Oasis Ecological Agriculture Area}

\subsubsection{General Principles}

The key to the industrialisation of oasis ecological agriculture is water. Qilian Mountain is the water conservation and supply area of the river in Hexi Corridor. In the oasis, scientific irrigation and drainage system should be set up, water resources should be reasonably distributed, and water-saving technology should be popularised.

Grassland is a fragile ecosystem in arid desert area on the edge of oasis, and its carrying capacity is very limited. Thus, the rehabilitation of grassland is really essential. Based on the local water, soil, light and heat resources, afforestation, green barrier construction, plastic film and greenhouse agriculture have to be developed in the desert area around the oasis. According to the initial investment constraints and operating cost constraints, we intend to develop a regional solar thermal or photovoltaic system for the ecology evolution in this zone.

\subsubsection{Energy Saving Based on Thermal Insulation of Rural Buildings}

The rural houses in this area mainly focus on energy-saving transformation, and adopt economic targeted thermal insulation system, which is consistent with the technical route adopted in Longxi area.

\subsubsection{Clean Heating Project}

There are two plans for RCHP including household photovoltaic power generation integrated with photo-thermal heating, and passive solar house. As for Plan A, household photovoltaic power generation integrated with photo-thermal heating, both domestic 
power and heating demands (hot water is involved too) are satisfied simultaneously, and the comprehensive efficiency of solar utilisation is increased remarkably. Meanwhile, the electricity consumption of peasant farmers is reduced substantially, which promotes peasant farmers' income in disguised form since the power generated by this system is connected to the municipal grid. When it is in continuous rainy or snowy weather or at night, low-temperature ASHP unit is employed as an auxiliary heat source to provide heat for peasant farmers, which reduces commodity energy consumption dramatically. In practice, the system operates automatically, and peasant farmers can adjust indoor air temperature by regulating the indoor fan speed, based on their personal sensations. The limitations of this scheme include: (1) the local solar energy resources are required to be abundant; (2) the local financial support is required to be sufficient; (3) the local commodity-market-service chain is complete and sustainable. Table 6 records the scheme details using Gaodunying Village as the case [18].

Table 6. Scheme details in Gaodunying Village.

\begin{tabular}{lll}
\hline Name & Unit & Value \\
\hline The number of solar thermal and photovoltaic panels & $/$ & 26 \\
Total effective area of the panels & $\mathrm{m}^{2}$ & 20.8 \\
The volume of heatingstorage tank with thermal insulation & $\mathrm{m}^{3}$ & 1.0 \\
The number of farmhouses involved in statistics & $/$ & 50 \\
Power generation per year & $\mathrm{kWh}$ & 3041 \\
On-grid offer & $\mathrm{RMB} / \mathrm{kWh}$ & 0.2987 \\
Electric power price with subsidies by the government & $\mathrm{RMB} / \mathrm{kWh}$ & 0.42 \\
Annual earnings from power generation & $\mathrm{RMB}$ & 2185.6 \\
Average ambient temperature in tests & ${ }^{\circ} \mathrm{C}$ & -2.0 \\
Mean indoor air temperature in tests & ${ }^{\circ} \mathrm{C}$ & 13.0 \\
Span of heating season & $\mathrm{Month}$ & 5 \\
Total power consumption in heating season & $\mathrm{kWh}$ & $6000-8000$ \\
Total cost for power consumption in heating season & $\mathrm{RMB}$ & $3000-4000$ \\
Net cost for power consumption in heating season & $\mathrm{RMB}$ & $1000-2000$
\end{tabular}

Note: the raw data in this table is part of field investigations in Gaodunying Village, Yuzhong County, provided by Reference [18]; Chinese Society for Urban Studies. 2020 Annual report on China building energy efficiency. China Architecture \& Building Press, Beijing, China. 2020.

As to Plan B, passive solar house, the working temperature range of this system is wide, and there is no anti-freezing problem in winter. The air will not corrode the heat collector and pipeline, and the air system has low requirements for air-tightness, which has little impact on the overall operation efficiency. The thermal collection rate of air is high, and the heating efficiency is enhanced without secondary heat exchange. Beyond heating season, indoor ventilation is realised through changing pipeline and corresponding valves to avoid overheating of the system. This scheme also provides fresh air which improves indoor air quality at the same time. The limitations of this scheme include requirements of rich solar resources and longer payback period. Table 7 preliminary estimates the heating cost by passive solar use in North China [18].

Table 7. Preliminary estimates of heating costby passive solar use in North China.

\begin{tabular}{ccccc}
\hline Location & Beijing & Lasa & Dunhuang & Lanzhou \\
\hline $\begin{array}{c}\text { Solar resources } \\
\text { in heating }\end{array}$ & $1267 \mathrm{MJ} / \mathrm{m}^{2}$ & $2917 \mathrm{MJ} / \mathrm{m}^{2}$ & $2221 \mathrm{MJ} / \mathrm{m}^{2}$ & $1244 \mathrm{MJ} / \mathrm{m}^{2}$ \\
season & & & & \\
Heating cost & $0.379 \mathrm{RMB} / \mathrm{kWh}$ & $0.176 \mathrm{RMB} / \mathrm{kWh}$ & $0.229 \mathrm{RMB} / \mathrm{kWh}$ & $0.383 \mathrm{RMB} / \mathrm{kWh}$ \\
Payback period & $14.64 \mathrm{a}$ & $6.01 \mathrm{a}$ & $7.99 \mathrm{a}$ & $14.83 \mathrm{a}$ \\
\hline
\end{tabular}

Note: the solar resources involved in statistics require that radiation intensity is higher than $400 \mathrm{~W} / \mathrm{m}^{2}$, and these data cited in the table is based on the ideal constructions under optimum solar collection states. 


\subsection{Yellow River Area}

\subsubsection{General Principles}

Due to the high terrain, water can only be diverted for irrigation. Thus, water conservancy facilities are the foundation of development. It is necessary to improve the multiple cropping indexes, concentrated on the development of high-quality and high-efficiency agriculture, and plant high-quality grain varieties in the rivers and valleys where there are more people and less land and good water and heat.

The rural development in this zone is highly dependent on the neighbouring cities and towns, and a variety of resources cannot be self-sufficient. In accordance with the regional economy, the key of clean heating is clean electricity. In economically underdeveloped areas, peasant farmers' income mainly comes from migrant workers. It is necessary to adhere to the ecological basis and improve the living environment of peasant farmers gradually.

\subsubsection{Energy Saving Based on Thermal Insulation of Rural Buildings}

The rural houses in this area mainly focus on energy-saving transformation, and adopt economic targeted thermal insulation system, which is consistent with the technical route adopted in Longxi area.

\subsubsection{Clean Heating Project}

There are two plans for RCHP including household photovoltaic power generation integrated with photo-thermal heating, and low-temperature ASHP air heater. As for Plan A, we have detailed in the case of Hexi Corridor area. As to Plan B, low-temperature ASHP air heater, we can install the unit in accordance with heating demand of peasant farmers. The mentioned installation is controlled independently when it is operated with the part-time and part-space patterns, which saves considerable costs. Since the indoor unit is installed on the ground, the hot air at the lower outlet flows close to the ground and rises slowly and naturally, so that the peasant farmers' ankles are warm and their feelings are comfortable. The upper air outlet of the installation is designed for the working area of peasant farmers, and the temperature in this zone rises quickly. Due to the indoor unit is terminal equipment, there is no need to add other devices for heating. In addition, the ASHP air heater has realised one key operation, and there is no pollutant emission. Hence this scheme is convenient and environmentally friendly.

The limitations of this scheme include: (1) local commodity-market-service chain is required to be complete and sustainable, including scheme design, equipment installation, adjustment, training for use, after-sales maintenance, and so forth; (2) local financial support is required to be sufficient and financing channels are unobstructed; (3) peasantfarmers ${ }^{\prime}$ disposable property is required to be abundant. Table 8 reports the scheme details based on the Gaodunying Village Data [18].

Table 8. Scheme details about low-temperature ASHP air heater used in Gaodunying Village.

\begin{tabular}{ccc}
\hline Name & Unit & Value \\
\hline The number of farmhouses involved in statistics & $/$ & 50 \\
Electric power price with subsidies by the government & $\mathrm{RMB} / \mathrm{kWh}$ & 0.42 \\
Average ambient temperature in tests & ${ }^{\circ} \mathrm{C}$ & -2.0 \\
Mean indoor air temperature in tests & ${ }^{\circ} \mathrm{C}$ & 13.0 \\
Span of heating season & Month & 5 \\
Total power consumption in heating season & $\mathrm{kWh}$ & $6000-8000$ \\
Total cost for power consumption in heating season & $\mathrm{RMB}$ & $3000-4000$ \\
\hline
\end{tabular}

Note: the raw data in this table is part of field investigations in Gaodunying Village, Yuzhong County, provided by Reference [18]; Chinese Society for Urban Studies. 2020 Annual report on China building energy efficiency. China Architecture \& Building Press, Beijing, China. 2020. 


\section{Conclusions and Policy Implications}

\subsection{Conclusions}

Rural Gansu has long been suffered from limited energy supply, unreasonable energyuse structure, unavailable or inefficient biomass energy use, and great pressure on ecological environment, due to its special natural geographical environment and economic factors.

According to the resource distribution and planning situation of the province, the execution of RCHP is zoned for six regions: Longdong zone with grass field ecological agriculture and animal husbandry industrial area; Longxi dry farming and rain collecting agricultural and livestock industrial area; Longnan Mountainous 3D ecological characteristic agricultural area; Gannan-Linxia artificial ecological grass and livestock industry area; Hexi Corridor oasis ecological agriculture area; and Yellow River area.

We can build a "gas-electricity-heat-fertiliser" cogeneration pattern with near zero carbon emission, which aims at ecological circular economic zone. Similarly, an "organic agriculture integrated with biomass briquette fuel forming and burning" mode can be set up towards characteristic agricultural and side line products processing circular economic zone. In the biomass-scarcity areas, by contrast, what we can do is multi-dimensionally comparing various technical schemes, and gradually boosting RCHP in accordance with local conditions.

More importantly, no matter in which zone, the thermal insulation of housing envelope needs improving urgently, which is the fundamental to RCHP in rural Gansu.

\subsection{Policy Implications}

In general, policy formulation has to be well-directed to fully consider the uneven distribution of resources, population, and economic development in Gansu Province. Meanwhile, the practice of RCHP in other provinces and states should be thoroughly concerned.

Both economic construction and livelihood improvement have to be based on ecological sustainability. The narrow pollution-treatment approach must be prohibited owing to the originally fragile ecology in Gansu Province.

In the areas with abundant biomass energy, building an ecological circulation cogeneration mode will take priority over all others. First off, a complete regional industrial chain has been set up, which enhances the flexibility and toughness of the economic ecological environment. Then the reasonable consumption of biomass resources has been realised, and a sustainable material cycle has been established.

In the regions with general application of biomass, it is necessary to explore biomass potentials and enhance agricultural economy chain, which completes the organic agriculture plus biomass fuel industry. Firstly, it strengthens the risk resistance ability of the regional economy. Secondly it reasonably absorbs the surplus agricultural waste and set up a sustainable ecological cycle.

As for the areas where all kinds of resources are very scarce, the peasant farmers' life is hard, and the primary work is the repair and insulation of rural houses. Thereafter, we can gradually promote poverty alleviation and RCHP.

The coordination among different departments needs to be strengthened. First of all, policy conflicts must be eliminated.

When implementing financial subsidies one has to fully consider the differences (economic, environmental, sustainable, etc.) between various technical schemes, and the scheme review should be taken the form of anonymous experts (Delphi technique).

We should make clear economic incentive policies and ensure subsidy security. A group of sustainable policies are the basis that the RCHP can be effectively implemented, since peasant farmers might abandon RCHP when their expenditure on heating rises steeply.

The government needs to strengthen scientific guidance of planning and technical path. The follow-up operation and maintenance have to be concerned too. Based on advanced experience, the government should also guide professionals to build clean heating standards. In the meantime, there should be third party to monitor RCHPs to revise the technical route based on quantitative measurement and objective evaluation. 
Refine the implementation plan and encourage peasant farmers to participate actively. A clear and feasible plan can help peasant farmers to understand that the RCHP will not only reduce their expenses of heating but also improve their living conditions. Hence, the RCHP is practicable.

We needto gradually improve the market-oriented operation mechanism, get rid of the excessive dependence on government subsidies, open up financing channels, and set up a benign cyclepattern of "enterprise oriented, government driven, and residents affordable".

The government has to guide the building of green development funds for poor and backward areas, support the issuance of green bonds by clean heating enterprises, finance the flow and exchange of talents, and actively encourage the introduction of private capital for the benefit of people.

Finally, tax levers should also be considered to support and guide peasant farmers' self-organised biomass cooperatives to conduct the "biomass energy poverty alleviation project".

Author Contributions: D.Q.: Conceptualization, Methodology, Investigation, Formal analysis, writing original draft, writing review and editing. X.D.: Investigation, Micro survey. J.W.: Writing review and editing, Micro survey. C.H.: Investigation, writing review and editing. G.W.: Project administration. F.Z.: Funding acquisition. S.L.: Project administration. All authors have read and agreed to the published version of the manuscript.

Funding: This work was financially supported by the National Natural Science Foundation of China (51978200\& 11962016) and the Science Foundation of Gansu Province Building Energy Saving (JK2021-10).

Institutional Review Board Statement: Not applicable.

Informed Consent Statement: Not applicable.

Data Availability Statement: The paper have stated all owners' name and accepted their allowance for publication.

Acknowledgments: The authors are grateful to all the research participants for generously sharing their experiences.

Conflicts of Interest: The authors declare that they have no known competing financial interest or personal relationships that could have appeared to influence the work reported in this paper.

\section{Nomenclature}

BES Building energy saving

CMS Conservation-minded society

IT IS Internal thermal insulation

NRC New Rural Construction

RCHP Rural clean heating project

\section{References}

1. Romero, C.A.T.; Castro, D.F.; Ortiz, J.H.; Khalaf, O.I.; Vargas, M.A. Synergy between Circular Economy and Industry 4.0: A Literature Review. Sustainability 2021, 13, 4331.

2. Rojas, C.N.; Peñafiel, G.A.A.; Buitrago, F.L.; Romero, C.A.T. Society 5.0: A Japanese Concept for a Superintelligent Society. Sustainability 2021, 13, 6567.

3. Dantas, T.E.T.; de-Souza, E.D.; Destro, I.R.; Hammes, G.; Rodriguez, C.M.T.; Soares, S.R. How the combination of Circular Economy and Industry 4.0 cancontribute towards achieving the Sustainable Development Goals. Sustain. Prod. Consum. 2021, 26, 213-227. [CrossRef]

4. $\quad$ Ding, Y.-J.; Li, C.-Y.; Wang, X.; Wang, Y.; Wang, S.-X.; Chang, Y.-P.; Qin, J.; Wang, S.-P.; Zhao, Q.-D.; Wang, Z.-R. An overview of climate change impacts on the society in China. Adv. Clim. Chang. Res. 2021, 12, 210-223. [CrossRef]

5. Mofijur, M.; Fattaha, I.M.R.; Alam, M.A.; Islam, A.B.M.; Ong, H.C.; Rahman, S.M.A.; Najafi, G.; Ahmed, S.F.; Uddin, M.A.; Mahlia, T.M.I. Impact of COVID-19 on the social, economic, environmental andenergy domains: Lessons learnt from a global pandemic. Sustain. Prod. Consum. 2021, 26, 343-359. [CrossRef] [PubMed] 
6. Asante, D.; He, Z.; Adjei, N.O.; Asante, B. Exploring the barriers to renewable energy adoption utilising MULTIMOORA-EDAS method. Energy Policy 2020, 142, 111479. [CrossRef]

7. Matthäus, D. Designing effective auctions for renewable energy support. Energy Policy 2020, 142, 111462. [CrossRef]

8. Gozgor, G.; Mahalik, M.K.; Demir, E.; Padhan, H. The impact of economic globalization on renewable energy in the OECD countries. Energy Policy 2020, 139, 111365. [CrossRef]

9. Clausen, L.T.; Rudolph, D. Renewable energy for sustainable rural development: Synergies and mismatches. Energy Policy 2020, 138, 111289. [CrossRef]

10. Haar, L. An empirical analysis of the fiscal incidence of renewable energy support in the European Union. Energy Policy 2020, 143, 111483. [CrossRef]

11. National Development and Reform Commission of China. Action Plan of Energy Revolution and Innovation (2016-2030). Available online: http:/ /www.nea.gov.cn/2016-06/01/c_135404377.htm (accessed on 1 June 2016).

12. National Energy Administration of China. 13th Five-Year Plan for Biomass Energy Development. 2016. Available online: http:/ / www.nea.gov.cn/2016-12/14/c_135904504.htm (accessed on 14 December 2016).

13. Qi, Y.; Zhang, X.L. Blueprint of Low Carbon Development; Social Sciences Academic Press: Beijing, China, 2018.

14. National Development and Reform Commission of China. Strategy of Revolution of Energy Production and Consumption (2016-2030). Available online: http:/ / www.gov.cn/xinwen/2017-04/25/5230568/files/286514af354e41578c57ca38d5c4935b.pdf (accessed on 25 April 2017).

15. National Development and Reform Commission of China. Notice on the Establishment and Improvement of Renewable Energy Electricity Consumption Guarantee Mechanism. 2019. Available online: http://zfxxgk.nea.gov.cn/auto87/201905/t20190515_36 62.htm (accessed on 15 May 2019).

16. National Development and Reform Commission of China. Overall Plan of Green Life Creation Action. 2019. Available online: http:/ / www.gov.cn/xinwen/2019-11/05/5448936/files/7a105ee3d9b24dec8a430dd9f64ef97f.pdf (accessed on 5 November 2019).

17. National Bureau of Statistics of China. China Statistical Yearbook. Available online: http://www.stats.gov.cn/tjsj/ndsj/ (accessed on 3 March 2021).

18. Chinese Society for Urban Studies. 2020 Annual Report on China Building Energy Efficiency; China Architecture \& Building Press: Beijing, China, 2020.

19. Ziemele, J.; Cilinskis, E.; Blumberga, D. Pathway and restriction in district heating systems development towards 4th generation district heating. Energy 2018, 152, 108-118. [CrossRef]

20. Sernhed, K.; Lygnerud, K.; Werner, S. Synthesis of recent Swedish district heating research. Energy 2018, 151, 126-132. [CrossRef]

21. Werner, S. International review of district heating and cooling. Energy 2017, 137, 617-631. [CrossRef]

22. Li, H.W.; Svendsen, S. Energy and exergy analysis of low temperature district heating network. Energy 2012, 45, 237-246. [CrossRef]

23. Soltero, V.M.; Chacartegui, R.; Ortiz, C.; Velazquez, R. Potential of biomass district heating systems in rural areas. Energy 2018, 156, 132-143. [CrossRef]

24. Hendricks, A.M.; Wagner, J.E.; Volk, T.A.; Newman, D.H.; Brown, T.R. A cost-effective evaluation of biomass district heating in rural communities. Appl. Energy 2016, 162, 561-569. [CrossRef]

25. Vallios, I.; Tsoutsos, T.; Papadakis, G. An applied methodology for assessment of the sustainability of biomass district heating systems. Int. J. Sustain. Energy 2016, 35, 267-294. [CrossRef]

26. Long, N.; Qu, D.H.; Li, W.Z.; Fu, X.H.; Yang, Y. Moisture proof calculation of envelope in severe cold zone. Heat. Vent. Air Cond. 2018, 48, 107-112.

27. Jin, S.L. Investigation on the model of dry farming circular ecological agriculture with farmer as unit in semi-arid rain fed agricultural area of Gansu Province. Commun. Agric. Sci. Technol. 2011, 2, 11-13.

28. He, W. A preliminary study on the mode of comprehensive agricultural development for poverty alleviation and ecological environment improvement in the poverty stricken mountainous areas of central and southern Gansu Province. Commun. Agric. Sci. Technol. 2008, 16, 16-17. 